\title{
KAJIAN KONDISI ATMOSFER TERKAIT BANJIR DI KABUPATEN CILACAP PADA TANGGAL 7 OKTOBER 2017
}

\author{
Mukhamad Adib Azka, Tesla Kadar Dzikiro, Juni Tika Simanjuntak, Paulus Agus \\ Winarso
}

\author{
Program Studi Meteorologi STMKG, STMKG, \\ Jln. Perhubungan 1 No. 5 Pondok Betung, Tangerang, Indonesia \\ Email: mukhamadadibazka9@gmail.com
}

\begin{abstract}
There have been floods in a number of areas of Cilacap Regency on Saturday, October 7, 2017. The flood was caused by extreme rainfall that occurred since Saturday (7/10) in the morning. The rainfall recorded at the Cilacap Meteorological Station falls into the extreme category because it reaches above $150 \mathrm{~mm}$ per day. These conditions indicate a significant atmospheric disturbance. Therefore, the incident was interesting to study related to the atmospheric conditions at that time. This study aims to describe atmospheric conditions on a global scale, regional scale, and local scale. The data used include the National Oceanic and Atmospheric Administration (NOAA), which includes Sea Surface Temperature (SPL) and its anomalies and Isobars; from the Bureau of Meteorology (BoM), the value of the Southern Oscillation Index (SOI) and the Madden-Julian Oscillation (MJO) phase diagram, renalysis data from the European Center for Medium-Range Weather Forecasts (ECMWF) which includes streamline, relative humidity, vorticity, and vertical velocity, surface data from Ogimet and Himawari 8 Satellite data from the Sub Division of BMKG Satellite Image Management. The results of the study showed that extreme rain that caused the flooding was due to the presence of active La Nina, active MJO, shear, and high humidity.
\end{abstract}

Keywords: weather disruption, extreme weather, ECMWF

\begin{abstract}
Abstrak: Telah terjadi banjir di sejumlah wilayah Kabupaten Cilacap pada hari Sabtu 7 Oktober 2017. Banjir tersebut diakibatkan oleh curah hujan ekstrem yang terjadi sejak Sabtu (7/10) dinihari. Curah hujan yang tercatat pada Stasiun Meteorologi Cilacap masuk dalam kategori ekstrem karena mencapai di atas $150 \mathrm{~mm}$ per hari. Kondisi tersebut menandakan adanya gangguan atmosfer yang cukup signifikan. Oleh karena itu, kejadian tersebut menarik untuk dikaji terkait dengan kondisi atmosfer pada saat itu. Kajian ini bertujuan untuk mendeskripsikan kondisi atmosfer pada skala global, skala regional, dan skala lokal. Data-data yang digunakan antara lain dari National Oceanic and Atmospheric Administration (NOAA), yang meliputi suhu permukaan laut (SPL) dan anomalinya serta Isobar; dari Bureau of Meteorology (BoM) yaitu nilai Southern Oscillation Index (SOI) dan diagram fase Madden-Julian Oscillation (MJO), data renalisis dari European Centre for Medium-Range Weather Forecasts (ECMWF) yang meliputi streamline, kelembaban relatif, vortisitas, dan vertical velocity, data permukaan dari ogimet serta data Satelit Himawari 8 dari Sub Bidang Pengelolaan Citra Satelit BMKG. Hasil kajian menunjukkan bahwa hujan ekstrem yang menyebabkan banjir tersebut dikarenakan adanya La Nina aktif, MJO aktif, pola shear, dan kelembaban udara yang tinggi.
\end{abstract}

Kata kunci: gangguan cuaca, cuaca eksterm, ECMWF

\section{PENDAHULUAN}

Dilansir berdasarkan berita dari detiknews bahwa terjadi curah hujan yang tinggi di wilayah Kabupaten Cilacap, Jawa Tengah selama dua hari terakhir ini. Akibatnya beberapa daerah di Cilacap terendam air hingga ketinggian $50 \mathrm{~cm}$. Berdasarkan hasil pengukuran curah hujan harian di Stasiun Meteorologi Cilacap hingga pukul 07.00 WIB tercatat mencapai 171,6 
milimeter. Kondisi tersebut sudah termasuk kategori hujan ekstrem karena mencapai di atas 150 milimeter per hari sehingga menyebabkan adanya genangan air di Kecamatan Cilacap Tengah, dan Cilacap Utara. Selain itu di Desa Kalijeruk, Kawunganten ketinggian air mencapai 1,5-2 meter. Hujan dengan intensitas tinggi mulai terjadi sekitar pukul 02.00 WIB dan air mulai naik sekitar pukul 04.00 WIB. Oleh karena itu, perlu adanya kajian terkait kondisi atmosfer pada saat terjadinya hujan lebat yang menyebabkan banjir di beberapa titik di Kabupaten Cilacap. Tujuan kajian ini yaitu untuk mengetahui kondisi atmosfer pada saat terjadinya hujan lebat tersebut.

Hujan merupakan jatuhan hidrometeor yang merupakan partikel-partikel yang memiliki diameter $0,5 \mathrm{~mm}$ atau lebih. Jika jatuhan hydrometeor itu mencapai tanah disebut hujan, akan tetapi apabila jatuhan hidrometeor tersebut tidak jatuh ke tanah karena menguap lagi, maka disebut virga (Soepangkat, 1994). Jumlah curah hujan $1 \mathrm{~mm}$ menunjukkan tinggi air hujan yang menutupi permukaan bumi sebesar $1 \mathrm{~mm}$, jika air tersebut tidak meresap ke dalam tanah atau menguap ke atmosfer (Tjasyono, 2006).

Sesuai dengan Peraturan Kepala BMKG (Badan Meteorologi Klimatologi dan Geofisika) nomor : KEP.009 tahun 2010 tentang Prosedur Standar Operasional Peringatan Dini, Pelaporan, dan Diseminasi Informasi Cuaca Ekstrem, skala lokal adalah fenomena meteorologi yang terjadi pada periode 1 (satu) menit sampai dengan 1 (satu) jam dengan jarak 1 (satu) kilometer $(\mathrm{km})$ hingga 100 (seratus) kilometer $(\mathrm{km})$. Skala regional adalah fenomena meteorologi yang terjadi pada periode 1 (satu) hari sampai dengan 1 (satu) minggu dengan jarak 100 (seratus) kilometer $(\mathrm{km})$ hingga 5000 (lima ribu) kilometer (km).

BMKG mengkategorikan intensitas curah hujan sebagai berikut:

a. Hujan ringan dengan intensitas $0,1-5,0 \mathrm{~mm} / \mathrm{jam}$ atau $5-20 \mathrm{~mm} / \mathrm{hari}$

b. Hujan sedang dengan intensitas $5,0-10,0 \mathrm{~mm} / \mathrm{jam}$ atau $20-50 \mathrm{~mm} / \mathrm{hari}$

c. Hujan lebat dengan intensitas $10,0-20 \mathrm{~mm} / \mathrm{jam}$ atau $50-100 \mathrm{~mm} / \mathrm{hari}$

d. Hujan sangat lebat dengan intensitas $>20 \mathrm{~mm} / \mathrm{jam}$ atau $>100 \mathrm{~mm} / \mathrm{hari}$

Gangguan cuaca merupakan kondisi dinamika udara yang secara cepat akan mengubah kondisi cuaca yang berbeda dari sebelumnya, misalnya dari kondisi cerah berubah ke kondisi berawan dan hujan atau sebaliknya. Dalam kenyatannya kondisi gangguan cuaca yang terjadi di alam khususnya di udara dapat dibedakan ke dalam tiga bagian yaitu:

1. Gangguan cuaca yang muncul akibat proses mekanis seperti konvergensi, divergensi, gelombang di atmosfer, dsb.

2. Gangguan cuaca yang muncul akibat proses thermis seperti konveksi, adveksi.

3. Gangguan cuaca yang muncul akibat gabungan proses mekanis dan proses thermis seperti front, ITCZ, palung tekanan rendah (Winarso, 2009).

\section{METODE PENELITIAN}

Kajian ini dilakukan di wilayah Cilacap pada tanggal 7 Oktober 2017 saat banjir tersebut terjadi yang sebelumnya diawali dengan curah hujan yang cukup lebat. Data yang digunakan pada penelitian ini antara lain : 
Tabel 1. Data penelitian dan sumbernya

\begin{tabular}{ccll}
\hline No & Skala & \multicolumn{1}{c}{ Data } & \multicolumn{1}{c}{ Sumber } \\
\hline 1 & & SPL Analisis dan Anomali & NOAA (National Oceanic and \\
2 & Skala Global & MJO (Madden-Jullian Oscillation) & Atmospheric Administration) \\
3 & & SOI (Southern Oscillation Index) & BoM (Bureau of Meteorology) \\
4 & & Isobar & NOAA (National Oceanic and \\
5 & & Streamline & Atmospheric Administration) \\
6 & Skala Regional & Kelembaban relatif & ECMWF (European Centre \\
7 & & Vortisitas & for Medium-Range Weather \\
8 & & Vertical velocity & Forecasts) \\
9 & \multirow{2}{*}{ Skala Lokal } & Data stasiun permukaan & Ogimet \\
10 & & Satelit Himawari 8 & BMKG \\
\hline
\end{tabular}

Data dari ECMWF merupakan data format nc sehingga diolah menggunakan software OpenGrADS. Hasil olahan tersebut menghasilkan gambar sesuai dengan parameter yang telah ditentukan dengan gradasi yang menunjukkan nilai dari masing-masing parameter tersebut. Pada kajian ini menggunakan metode analisis dekriptif yaitu dengan menjelaskan masingmasing parameter yang telah ditentukan sehingga dapat diketahui kondisi atmosfer pada saat kejadian tersebut.

\section{PEMBAHASAN}

\subsection{Kajian Skala Global}

\subsubsection{Kajian suhu permukaan laut (SPL) dan anomalinya}

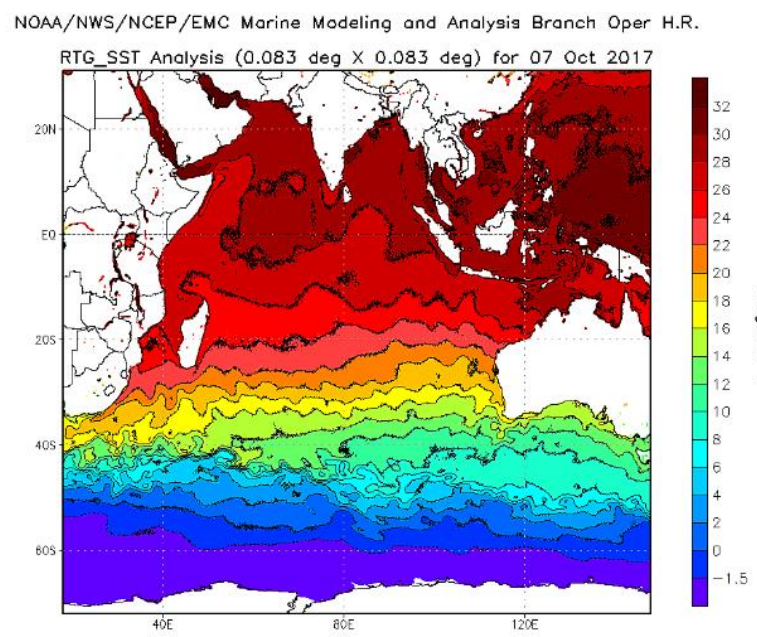

a

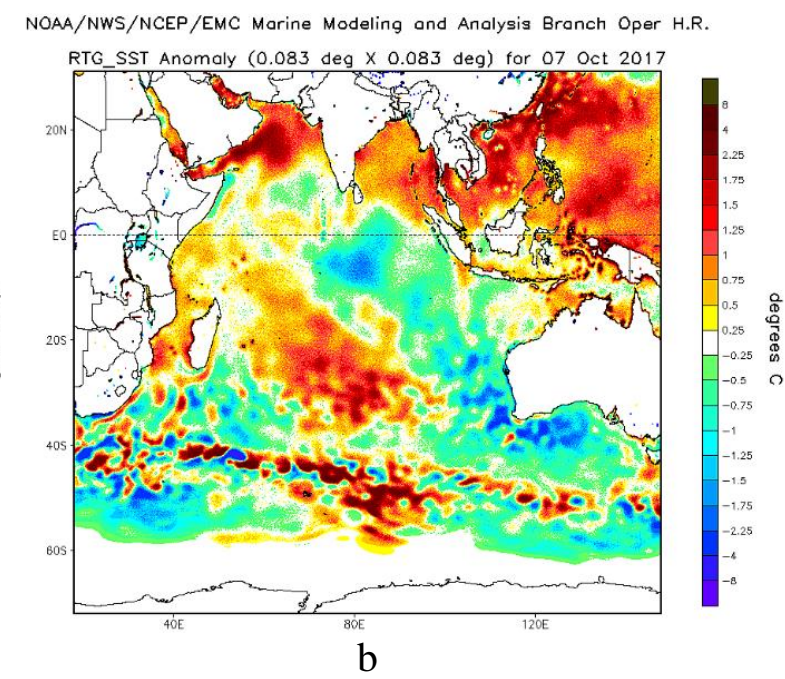

b

Gambar 1. a) suhu permukaan laut b) anomali suhu permukaan laut (http://polar.ncep.noaa.gov/sst/ophi/archive/20171007/)

Gambar di atas merupakan suhu permukaan laut dan anomalinya yang didapat dari NOAA (National Oceanic and Atmospheric Administration). Pada gambar terkihat bahwa wilayah perairan Indonesia secara umum tergolong hangat. Di perairan sekitar Cilacap, suhu 
permukaan laut berkisar antara $26-28{ }^{\circ} \mathrm{C}$ dengan anomali bernilai negatif yang artinya suhu permukaan laut cenderung lebih dingin dari kondisi normalnya. Sedangkan, di perairan utara Jawa memiliki anomali positif yang berarti suhu permukaan laut lebih hangat dari kondisi normalnya. Hal ini sangat memungkinkan sebagai sumber penguapan dan memicu berkumpulnya massa udara di atas wilayah Jawa.

\subsubsection{Kajian Madden Julian Oscillation (MJO)}

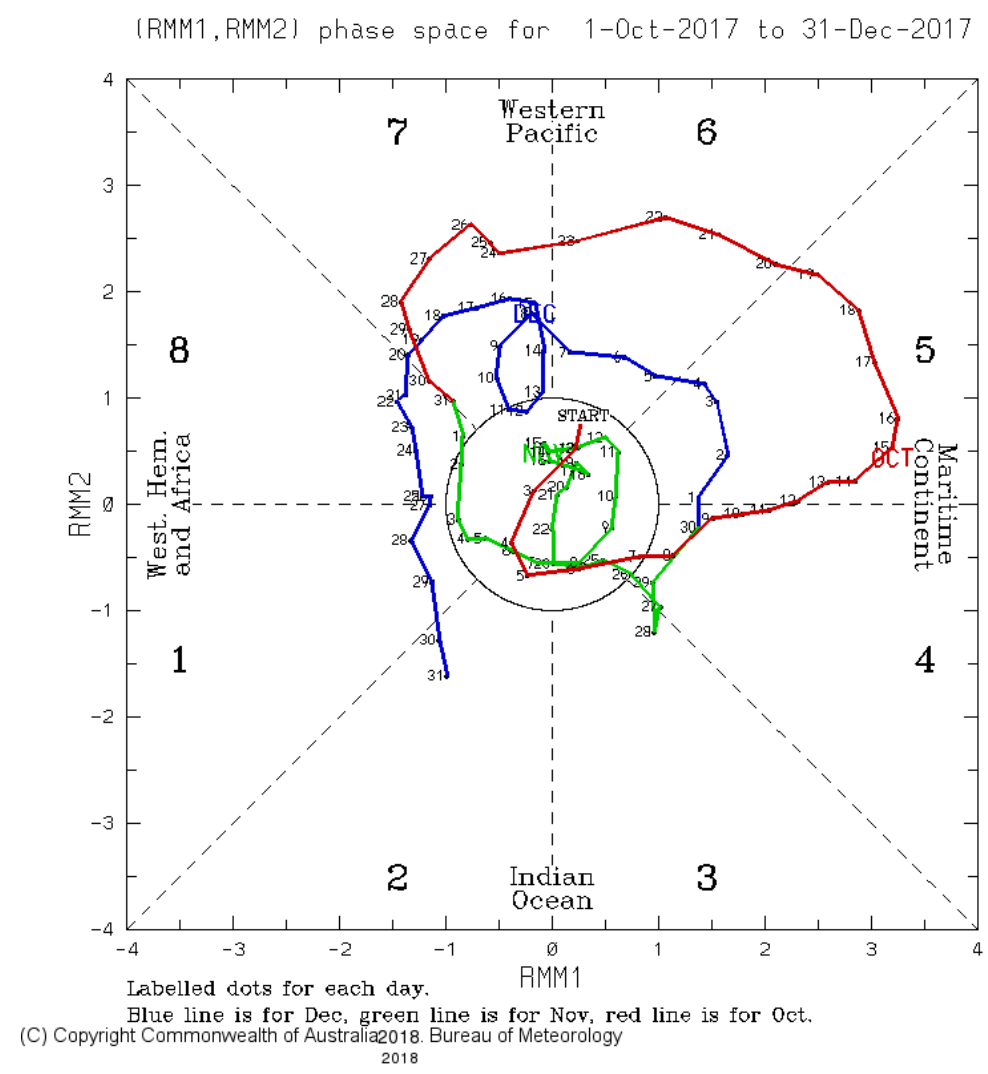

Gambar 2. Diagram fase MJO (http://www.bom.gov.au/climate/mjo/\#tabs=MJO-phase)

Madden Julian Oscillation (MJO) adalah suatu gelombang atau osilasi sub musiman yang terjadi di lapisan troposfer wilayah tropis, akibat dari sirkulasi sel skala besar di ekuatorial yang bergerak dari barat ke timur yaitu dari laut Hindia ke Pasifik Tengah dengan rentang daerah propagasi $15^{\circ} \mathrm{LU}-15^{\circ} \mathrm{LS}$. MJO secara alami terbentuk dari sistem interaksi laut dan atmosfer, dengan periode osilasi kurang lebih 30-60 hari (Madden dan Julian, 1971). Gambar di atas merupakan diagram fase Madden-Jullian Oscillation (MJO). Diagram fase mengilustrasikan lokasi penjalaran MJO. Pada tanggal 7 Oktober 2017, MJO berada di fase 4 yang merupakan Maritime Continent termasuk didalamnya benua maritim Indonesia. Indeks MJO pada tanggal 7 Oktober 2017 berada di dalam lingkaran yang menandakan MJO aktif dalam intensitas yang lemah. 


\subsubsection{Kajian Southern Oscillation Index (SOI)}

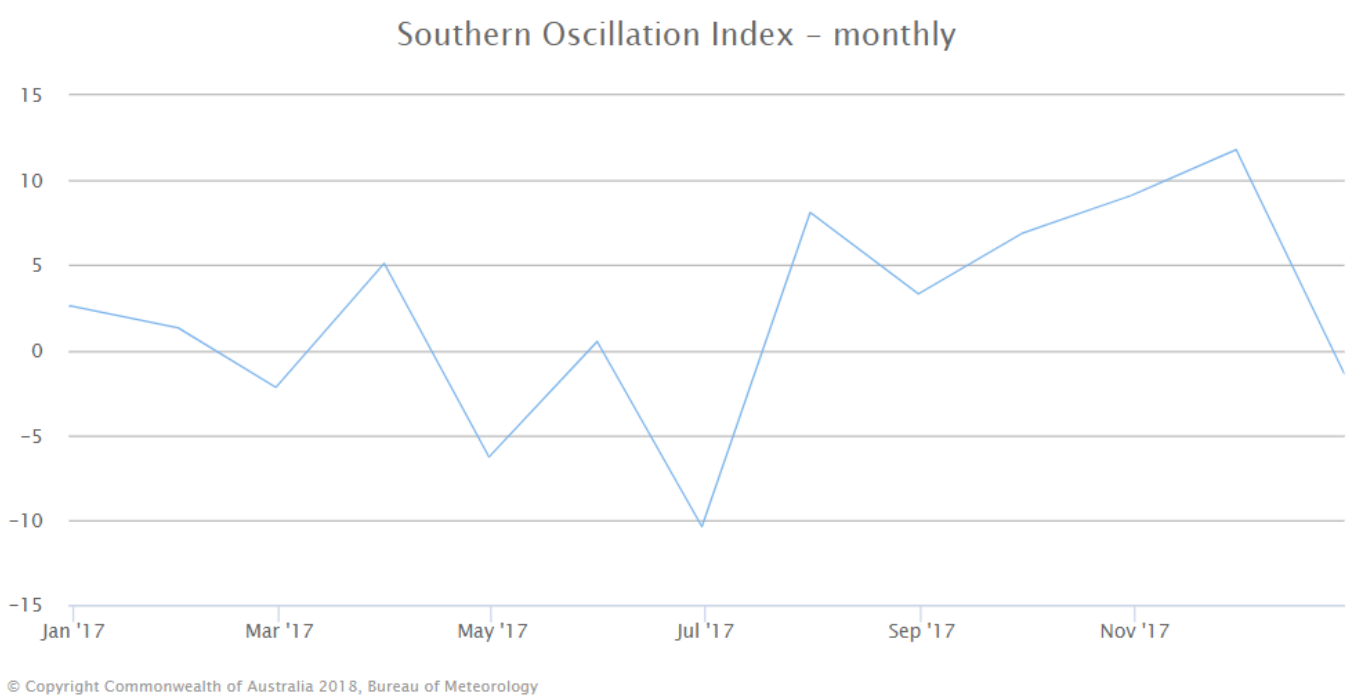

Gambar 3. Nilai Southern Oscillation Index

(http://www.bom.gov.au/climate/current/soihtm1.shtml)

Indeks SOI ini secara sederhana merupakan perbedaan tekanan udara permukaan di daerah Pasifik Timur yang diukur di Tahiti, dengan tekanan udara permukaan di daerah Pasifik Barat (Indo-Australia) yang diukur di Darwin, Australia (Haryanto, 1998). Gambar di atas merupakan grafik nilai SOI. Terlihat bahwa pada Bulan Oktober 2017 SOI berada pada rentang nilai $7-10$. Menurut Bureau of Meteorology indeks positif lebih dari 7 menandakan bahwa bulan tersebut La Nina sedang aktif dalam intensitas yang lemah. Artinya, massa udara akan bergerak menuju kawasan Indonesia sehingga terbentul awan-awan konvektif lebih banyak. Kondisi ini berpotensi untuk terjadinya hujan lebat.

\subsection{Kajian Skala Regional}

\subsubsection{Kajian Streamline}
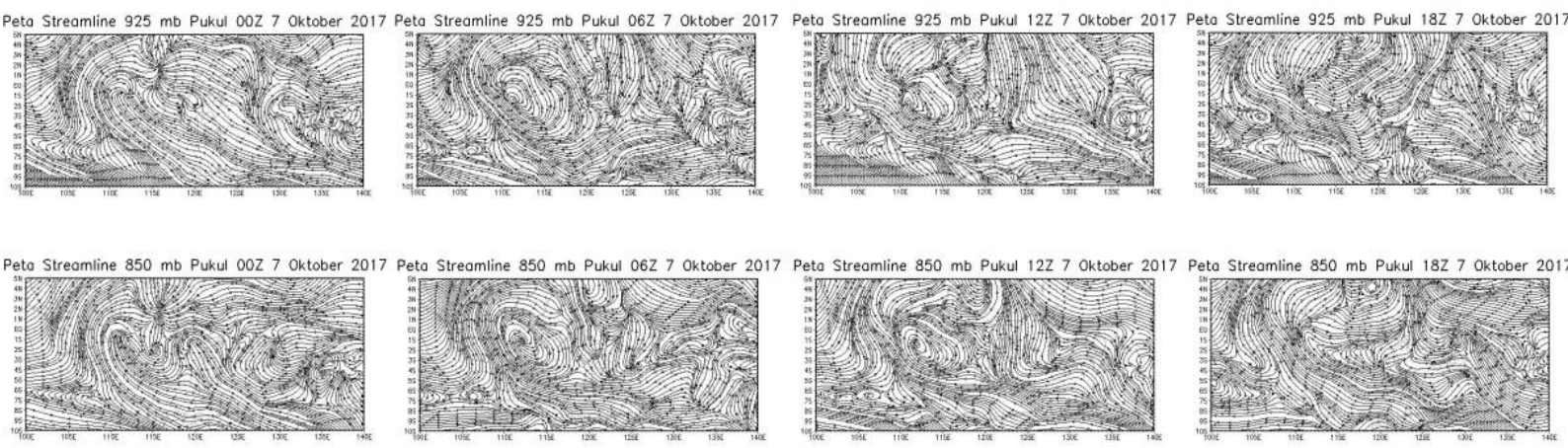

Gambar 4. Streamline lapisan 925 mb dan $850 \mathrm{mb} 7$ Oktober 2017

Gambar di atas merupakan streamline pada lapisan $925 \mathrm{mb}$ dan $850 \mathrm{mb}$ tanggal 7 Oktober 2017. Terlihat bahwa terdapat shear atau belokan massa udara di sekitar Cilacap terjadi mulai pukul 01.00 WIB dinihari. Sehingga memungkinkan untuk terbentuknya awan akibat adanya shear atau belokan massa udara yang memicu terjadinya konvergensi. 


\subsubsection{Kajian Isobar}
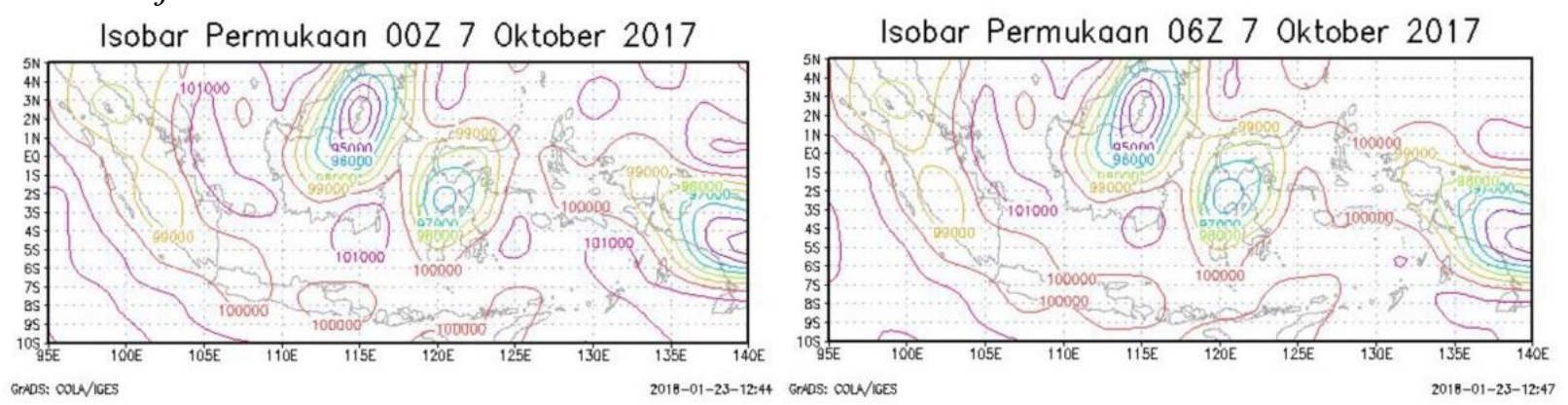

GrRS: CON/IGES

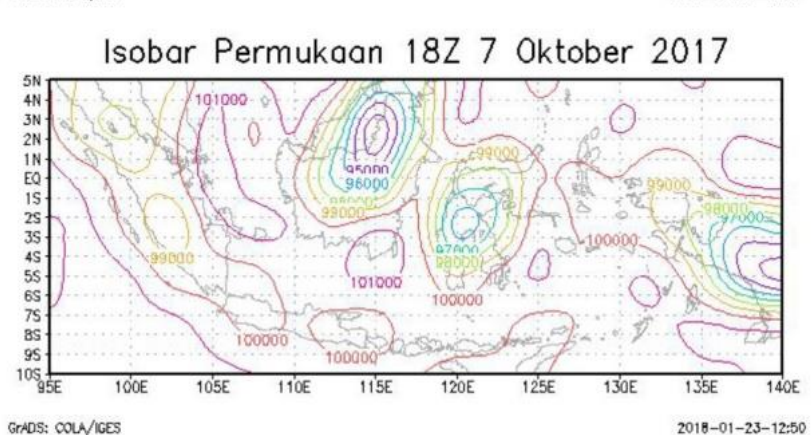

Isobar Permukaan $12 Z 7$ Oktober 2017

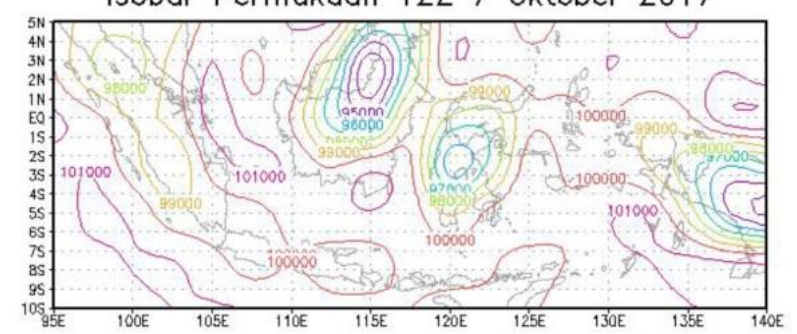

GrNOS: COLN/IES

Gambar 5. Isobar 7 Oktober 2017

Gambar di atas merupakan gambar kondisi tekanan udara permukaan pada 7 Oktober 2017. Pada gambar terlihat bahwa terdapat daerah konvergensi atau pertemuan massa udara di daerah sekitar Cilacap. Kondisi ini menyebabkan terjadinya pembentukan awan-awan konvektif di daerah Cilacap yang menyebabkan adanya potensi hujan lebat di wilayah Cilacap.

\subsubsection{Kajian $R H$}

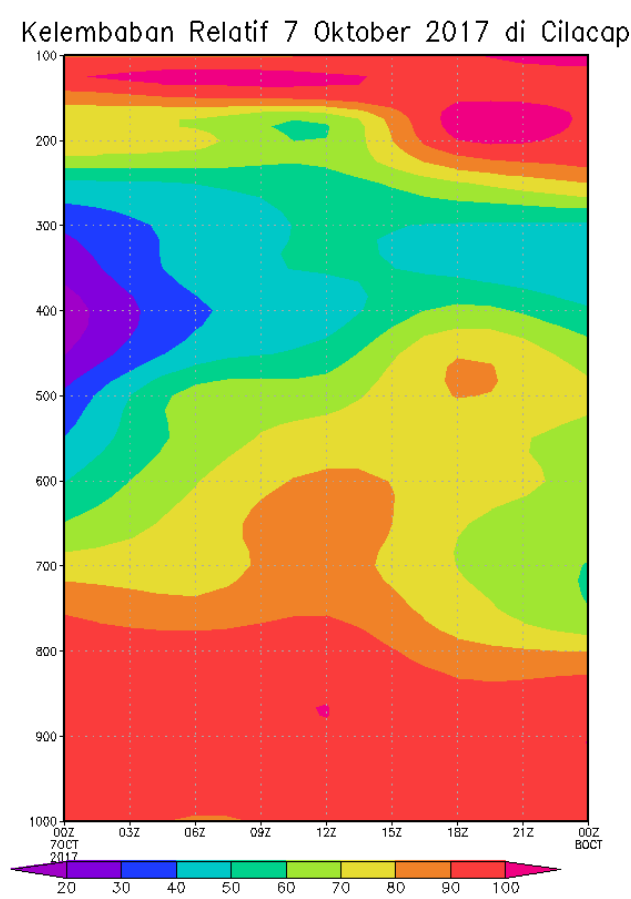

Gambar 6. Kelembaban relatif 7 Oktober 2017 di Cilacap 
Gambar di atas merupakan kelembaban relatif pada 7 Oktober 2017 di titik pengamatan Stasiun Meteorologi Cilacap. Terlihat bahwa nilai kelembaban udara sangat tinggi pada lapisan $900-800 \mathrm{mb}$ yaitu $90 \%$ yang menandakkan adanya proses kondensasi yang cukup signifikan di lapisan rendah tersebut sehingga memicu berkumpulnya uap air penghasil awan hujan.

\subsubsection{Kajian Vortisitas}

Vortisitas merupakan nilai ukuran pada gerak memutar atau rotasi (Wirjohamidjojo, 2013). Vortisitas dapat pula diartikan sebagai gerak rotasi udara dalam skala mikro. Komponen vertikal dari vortisitas cukup banyak digunakan dalam aplikasi dan prediksi cuaca meteorologi.

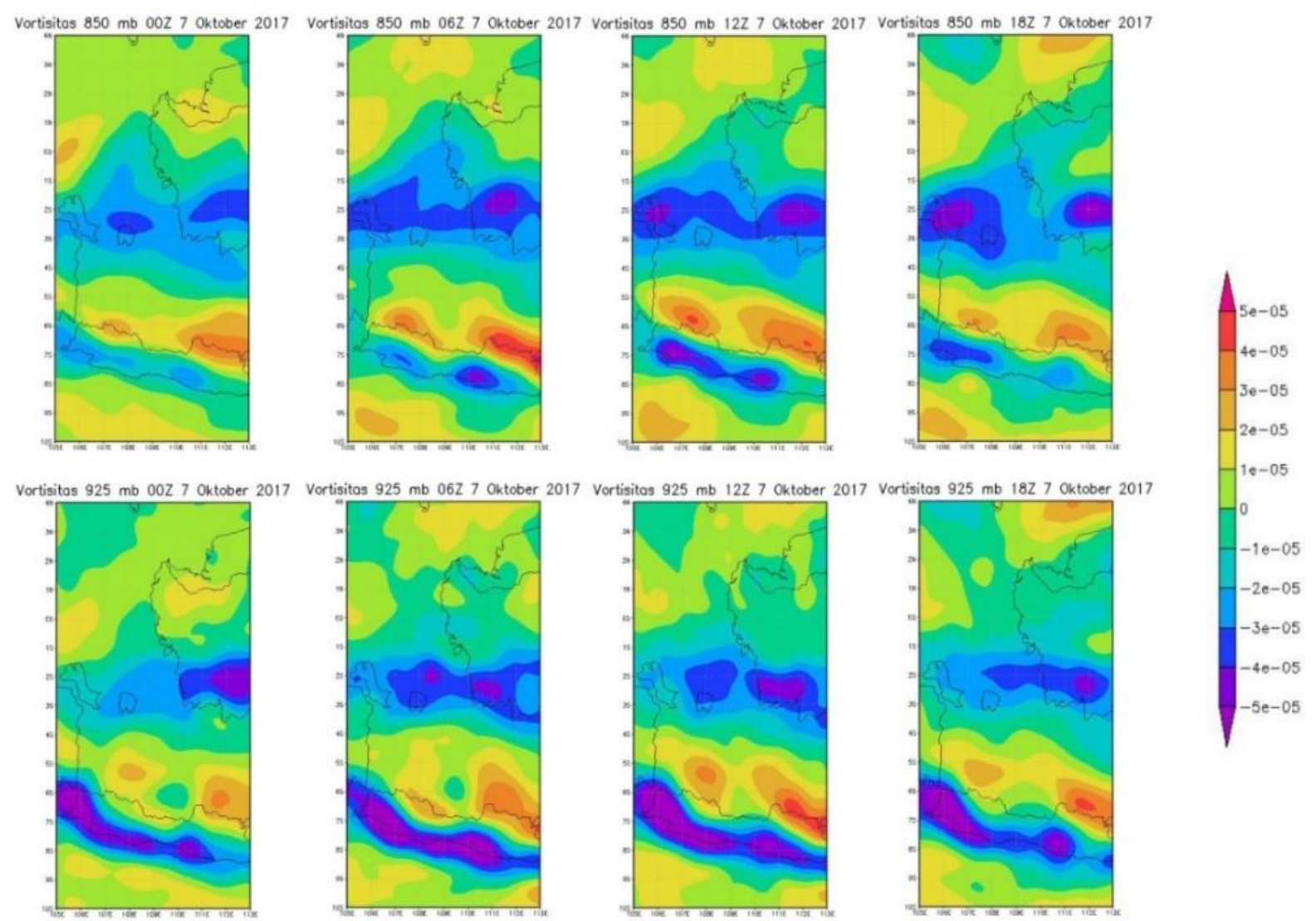

Gambar 7. Vortisitas lapisan 925 mb dan 850 mb 7 Oktober 2017

Gambar di atas merupakan gambar nilai vortisitas pada lapisan $925 \mathrm{mb}$ dan $850 \mathrm{mb}$ pada tanggal 7 Oktober 2018. Terlihat bahwa vortisitas bernilai negatif di Belahan Bumi Selatan (BBS) yang menandakkan bahwa udara cenderung bergerak ke atas dan membentuk pola siklonik (konveksi).

\subsubsection{Kajian Vertical Velocity}

Nilai vertical velocity merupakan nilai untuk mengukur suatu gerakan massa udara dalam bidang vertikal. Satuan vertical velocity menggunakan $\mathrm{mb} / \mathrm{s}$ (milibar per second) atau $\mathrm{Pa} / \mathrm{s}$ (pascal per second). Nilai negatif pada vertical velocity menunjukkan pengurangan nilai tekanan per detik dalam bidang vertikal atau terdapat gerakan ke atas dari suatu massa udara, 
sedangkan nilai positif menunjukkan penambahan nilai tekanan per detik dalam bidang vertikal atau terdapat gerakan turun atau ke bawah dari suatu massa udara (Holton, 2004).

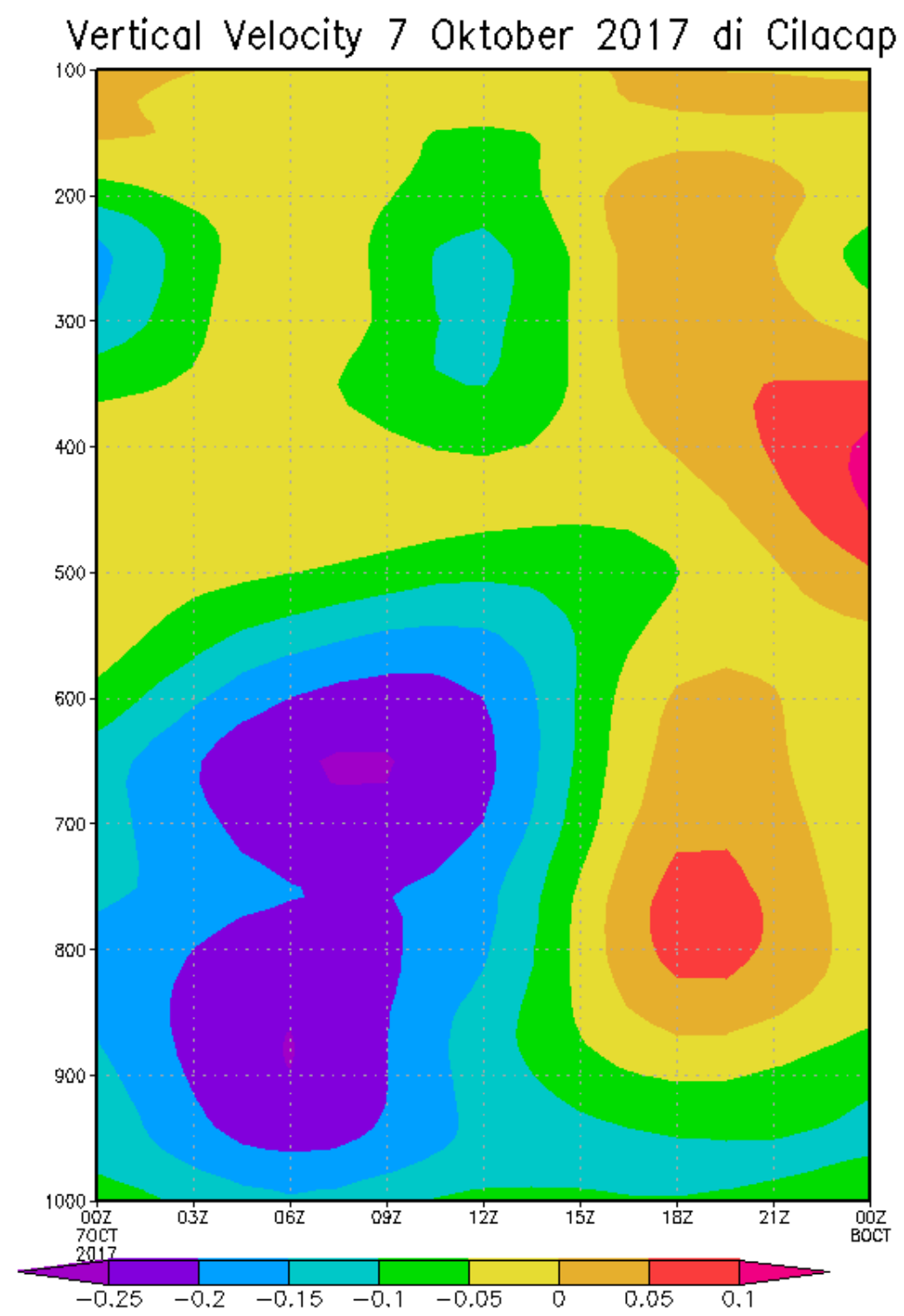

Gambar 8. Vertical velocity 7 Oktober 2017 di Cilacap

Gambar di atas merupakan nilai vertical velocity di titik stasiun pengamatan Meteorologi Cilacap. Pada titik Stasiun Meteorologi Cilacap menunjukan bahwa vertical velocity bernilai negatif pada jam 10.00 WIB sampai dengan 16.00 WIB pada lapisan $950 \mathrm{mb}$ hingga $600 \mathrm{mb}$. Hal ini menunjukan bahwa pada rentang jam tersebut terdapat gerakan ke atas dari massa udara sehingga mulai terbentuk awan-awan konvektif. Sedangkan, pada jam 01.00 WIB terlihat nilai verical velocity positif yang artinya terdapat gerakan turun dari suatu partikel atau massa udara yaitu tetes-tetes hujan. 


\subsection{Kajian Skala Lokal}

\subsubsection{Kajian Satelit Himawari}

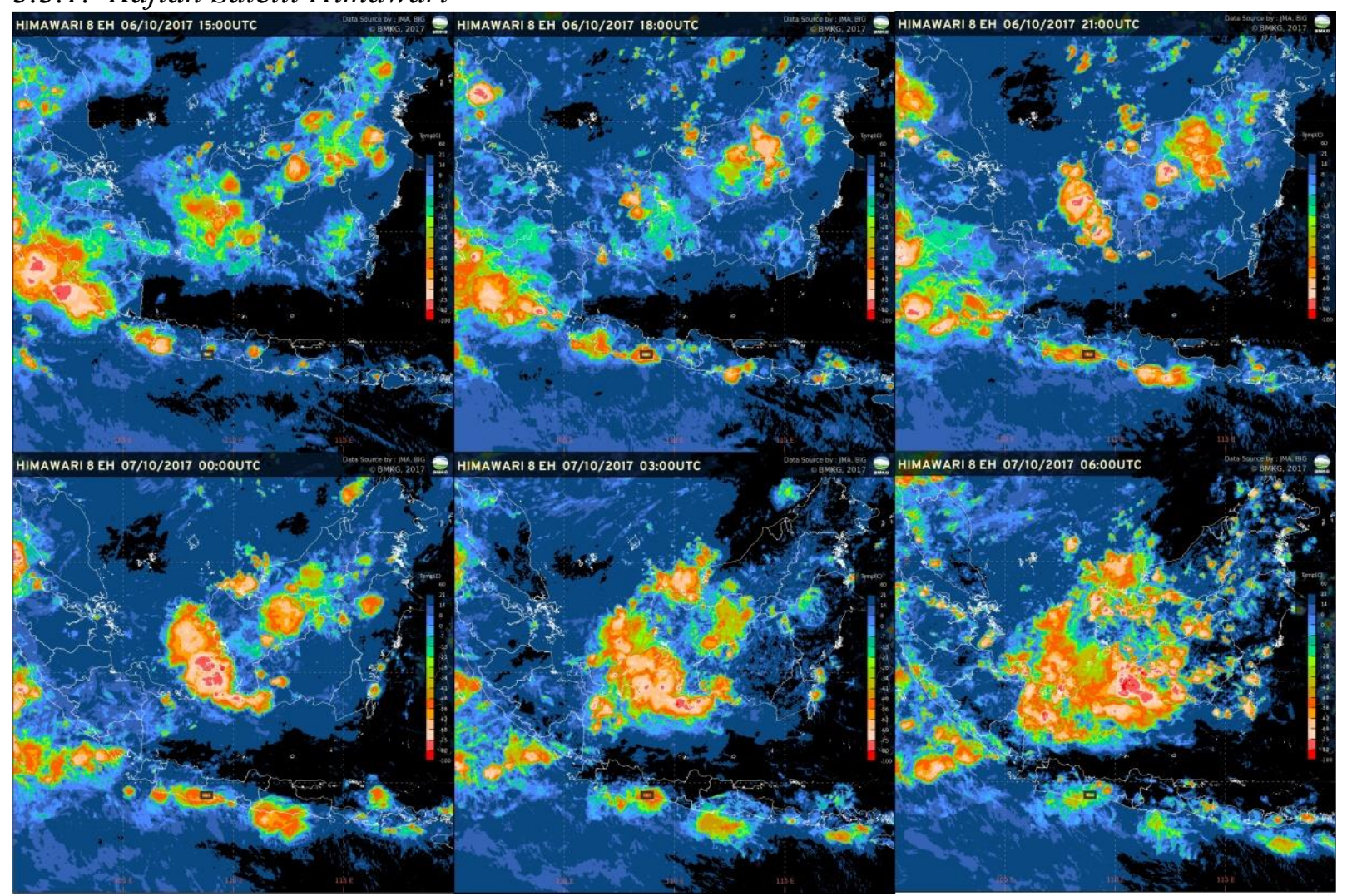

Gambar 9. Citra satelit Himawari-8 kanal infrared 7 Oktober 2017

Gambar di atas merupakan gambar pertumbuhan awan dari citra Satelit Himawari-8 kanal infrared. Terlihat bahwa di wilayah Cilacap terlihat bahwa awan konvektif sudah mulai tumbuh mulai pukul 22.00 WIB dilihat dari gambar citra satelit Himawari-8 kanal infrared yang berwarna merah. Terlihat pada gambar, suhu puncak awan di wilayah Cilacap berkisar antara $-48^{0} \mathrm{C}$ sampai dengan $-69^{\circ} \mathrm{C}$ yang menandakan adanya awan konvektif hingga lapisan tinggi yaitu Cumulonimbus $(\mathrm{Cb})$. 


\subsubsection{Kajian Data Permukaan}

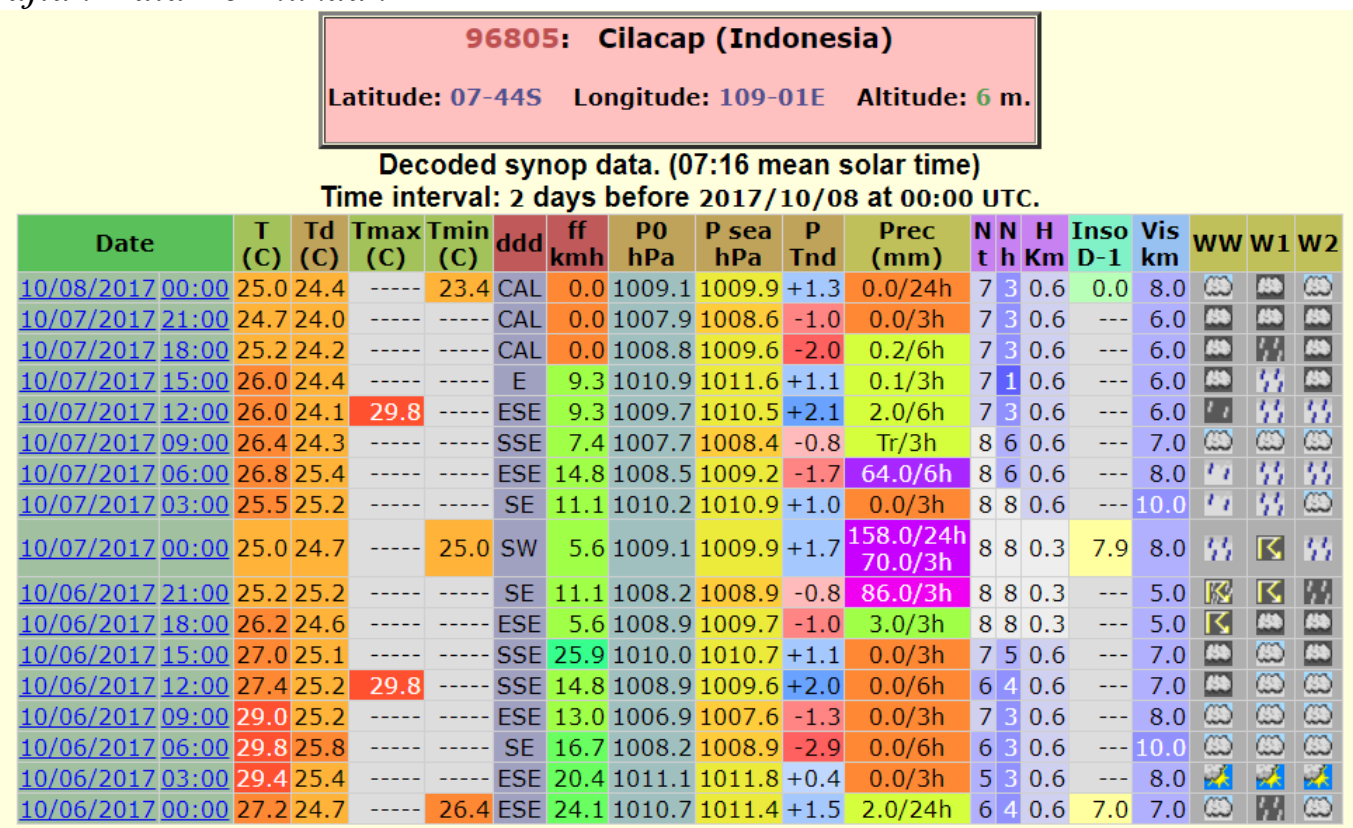

Gambar 10. Data pengamatan permukaan Stasiun Meteorologi Cilacap

Pada tanggal 07 Oktober 2017 pukul 00.00 UTC didapatkan curah hujan terukur 158.0 $\mathrm{mm} /$ hari. Hal itu menunjukkan bahwa di Kabupaten Cilacap terjadi curah hujan sangat lebat terutama pada dini hari seperti pada gambar di atas. Menurut BMKG (2010) curah hujan $>100$ $\mathrm{mm} /$ hari merupakan kategori hujan sangat lebat. Hujan yang sangat lebat inilah yang menyebabkan terjadinya banjir di wilayah Cilacap.

\section{KESIMPULAN}

Pada kajian ini, dapat disimpulkan bahwa penyebab terjadinya curah hujan tinggi yang menyebabkan terjadinya banjir di wilayah Cilacap yaitu La Nina aktif dengan intensitas lemah yang menyebabkan adanya peningkatan curah hujan dari normalnya. Selain itu, terdapat juga Madden-Jullian Oscillation (MJO) aktif dengan intensitas lemah yang menyebabkan awan-awan hujan banyak terkumpul di wilayah benua maritim Indonesia. Pola shear yang terdapat di atas wilayah Jawa juga menyebabkan banyak terbentuknya awan-awan hujan. Keadaan lokal seperti nilai kelembaban udara juga menyebabkan banyak terkumpul uap air yang berkondensasi di wilayah Cilacap.

\section{SARAN}

Kajian ini diharapkan dapat memberikan gambaran kondisi atmosfer yang terjadi sebelum, saat kejadian, dan sesudah kejadian hujan lebat. Sehingga, perlu adanya upaya mitigasi dari pihak yang terkait setelah adanya peringatan dini cuaca ekstrem yang dikeluarkan BMKG. Selain itu, pada kajian ini juga diperlukan tambahan parameter-parameter yang lain sehingga akan melengkapi dan menyempurnakan hasil kajian di masa yang akan dating.

\section{DAFTAR PUSTAKA}

BMKG. (2010). Peraturan Kepala Badan Meteorologi Klimatologi dan Geofisika Nomor: KEP.009 Tahun 2010 tentang Prosedur Standar Operasional Pelaksanaan Peringatan Dini, Pelaporan, dan Desiminasi Informasi Cuaca Ekstrim. BMKG. 
Jakarta

Haryanto, U. (1998). Keterkaitan Fase SOI terhadap Curah Hujan di DAS Citarum. http://repository. ipb.ac.id/bitstream/handle/ 123456789/ 4016/1998 uha.pdf? sequence $=$. diakses tanggal 3 November 2018

Holton, J. R. (2004). An Introduction to Dynamic Meteorology (4th edition). Elsevier Academic Press. San Diego-California.

Madden, R.A., dan P.R. Julian, (1971). Detection of a 40-50 day oscillation in the wind in the tropical Pasific. J. Atmos. Sci., 28, 702-708

Soepangkat. (1994). Pengantar Meteorologi. Departemen Perhubungan. Jakarta

Tjasyono, Bayong H.K. dan Harijono, Sri Woro B. (2006). Meteorologi Indonesia 2: Awan dan Hujan Monsun. Badan Meteorologi Klimatologi dan Geofisika. Jakarta.

Winarso, Paulus Agus. 2009. Analisa Cuaca II. Akademi Meteorologi dan Geofisika. Jakarta.

Wirjohamidjojo, S, (2013), Meteorologi Sinoptik, Badan Meteorologi Klimatologi dan Geofisika

http://polar.ncep.noaa.gov/sst/ophi/archive/20171007/ diakses pada 3 November 2018

http://www.bom.gov.au/climate/current/soihtm1.shtml diakses pada 3 November 2018

http://www.bom.gov.au/climate/mjo/\#tabs=MJO-phase diakses pada 2 November 2018

https://news.detik.com/berita-jawa-tengah/d-3674456/curah-hujan-tinggi-sebabkan-cilacapbanjir diakses pada 2 November 2018. 